\title{
We Don't Know What We Don't Know
}

\author{
ALAN N BEARD, \\ Department of Civil \& Offshore Engineering \\ Heriot-Watt University \\ Edinburgh, Scotland, U.K.
}

\begin{abstract}
In carrying out decision-making on risk then: $\{1\}$ There may be possible sequences which are not known about or $\{2\}$ There may be possible sequences which are known about but which are effectively ignored for one reason or another. It follows from this that we need to: $\{a\}$ Be willing to question our assumptions, $\{b\}$ Consciously try to be 'creative' in carrying out risk assessments, $\{\mathrm{c}\}$ Be open and explicit, $\{\mathrm{d}\}$ Look at a particular case from different points of view and using different models and $\{\mathrm{e}\}$ Err on the cautious side in making decisions on risk, to try to allow for the un-anticipated.
\end{abstract}

KEYWORDS: risk, assessment, modelling, assumptions, hazard

\section{INTRODUCTION}

The general move away from 'prescriptive' regulations to 'performance-based' regulations, with respect to decision-making on fire risk, implies a reliance on being able to assess the risk. Furthermore, in many countries, it has resulted in an increasing trend towards quantification, albeit that real-world decision-making may be tempered by concepts such as 'best practice' and other, essentially qualitative, concepts. If there is to be an increasing use of quantification in decision-making then it becomes increasingly important that the models which are used to gauge the risk be employed in an appropriate way and that we be as aware as possible of the limitations of those models.

The models used in aiding decision-making on fire risk are basically of two kinds, ie probabilistic and deterministic. Decisions may be made, in principle, on the basis that the risk should be within an 'acceptable range'. Of course this raises the question of 'acceptable to whom?' which creates a veritable ocean of issues which it is not the intention to go into in this paper. Instead, this article will discuss briefly a specific problem which arises when attempting to assess risk, whether quantitatively or qualitatively, and explores its ramifications to some degree. The argument will be couched in terms of quantitative modelling for clarity of explanation, but the problem is there for both quantitative and qualitative modelling. 


\section{CLOSED AND OPEN PREDICTIVE SYSTEMS}

For simplicity of argument and illustration the discussion will be continued in probabilistic terms, although the point is not limited to that point of view. In fact there appears to be an overall trend towards frameworks which are essentially probabilistic [1,2], although such frameworks may include significant deterministic elements. Quite apart from issues of uncertainty, sensitivity, reliability, appropriate use of models etc, which have been considered elsewhere, eg $[3,4]$, there is a basic problem in that we don't know what we have not thought of. This problem is not new, it was raised by Plato in the Socratic dialogue Meno [5], where Meno says "Why, on what lines will you look, Socrates, for a thing of whose nature you know nothing at all ?" Plato's reply, put into the the mouth of Socrates, is that "the soul is immortal and has ....acquired knowledge of all and everything". Learning or acquiring seemingly new knowledge becomes then an act of "remembering" or "recollection". While Plato's answer to the question may not take one very far in the real world, the question is just as relevant today as ever.

If a coin is tossed then it may be assumed that there are only two possible outcomes, ie heads $(\mathrm{H})$ or tails $(\mathrm{T})$. (Purists might say that there is the possibility of the coin resting on its side, assuming the side to correspond to a cylinder, so let's consider a very thin coin, tending to the limit of zero width.) The set representing the 'Universe of Discourse', $\Omega$, consists of two equal areas as in Figure 1. In mathematical language, such a case may be called 'complete', ie all possible outcomes are known. If we were to allow the coin to become thicker then we might consider a third possible outcome corresponding to the case in which the coin rests on its side (S); assuming the side to be cylindrical and not rounded. The set representing the universe of discourse for a thicker coin would then include an area representing this third possibility as well as the other two. In fact in considering this simple case one can see already how the simpler representation, where there are only two possible outcomes assumed, corresponds to a conceptual abstraction and not the real world. All our models are, in the final analysis, conceptual abstractions. In our ignorance we may convince ourselves that we have a reasonable estimate of risk and then decide that the estimated risk is within an acceptable range. However it is virtually certain that there will always be something which has not been thought of . More generally, there will always be sequences which have not been taken into account, whether they have been thought of or not.

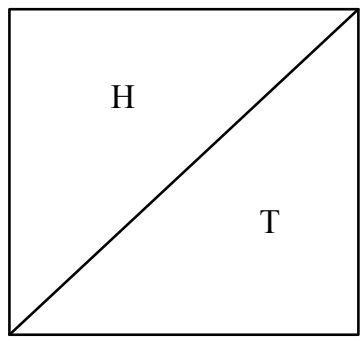

Figure 1 : Universe of Discourse $(\Omega)$ for the toss of a coin, assuming two possible outcomes only; heads ( H ) and tails ( T ) 
Models in which all possible outcomes are known have been called by Blockley [6] "closed world" models and the converse "open world" models. In the real world we are always dealing with open world models. Blockley also identifies four types of problems:

Type 1: Where all of the consequences of adopting a conjectural solution are known for certain.

Type 2: Where all of the consequences of adopting a conjectural solution have been precisely identified but only the probabilities of occurrence are known.

Type 3: Where all of the consequences of adopting a conjectural solution have been approximately identified so that only the possibilities of ill-defined or fuzzy consequences are known.

Type 4: Where only some of the consequences (precise or fuzzy) of adopting a conjectural solution have been identified.

Types 1,2 and 3 all invlove a closed world assumption whereas type 4 problems are those of real world decision-making and correspond to the need for an open world model.

A general reaction to this might be to say 'of course there may be possibilities which we have not taken account of, but these would be expected to be incredible'. Another, similar but rather different, reaction might be to say 'of course there will be possibilities which we have not taken account of but these may be regarded as of small likelihood and negligible'.

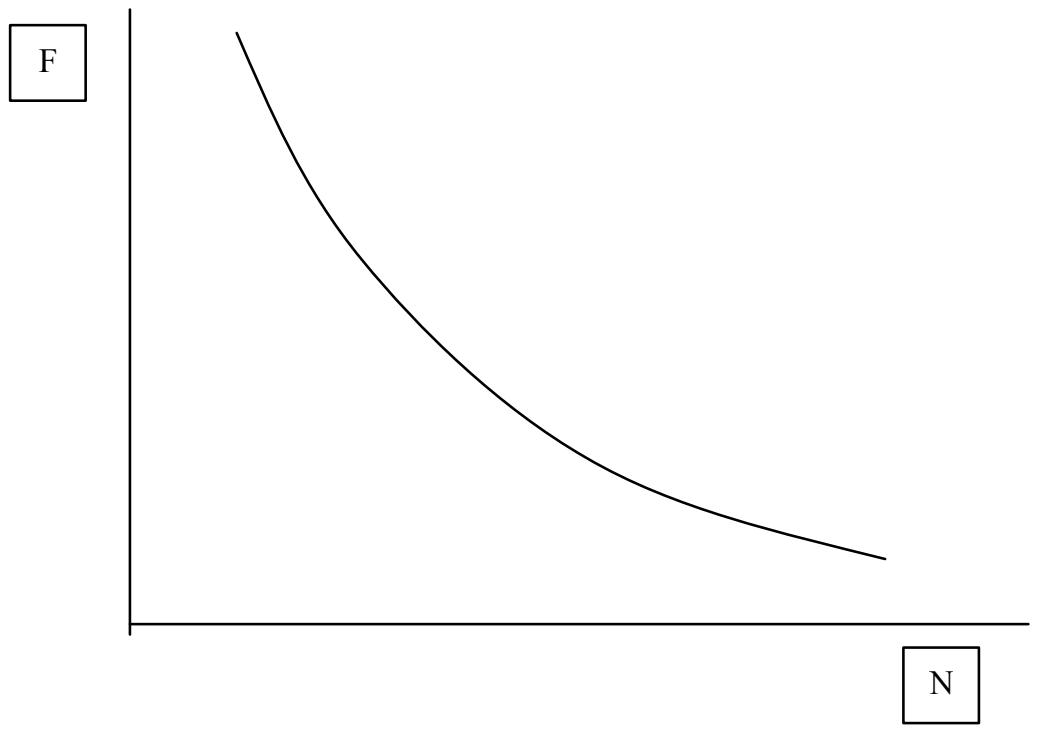

Figure 2: Schematic F-N Diagram. ( F - Frequency of N fatalities or more, per year $\mathrm{N}$ - Number of fatalities. F-N curves are often shown as straight lines on logarithmic graph paper) 
However, what we have not taken account of may not be incredible or may not be quantitatively negligible. Also, even if a particular sequence has a relatively small probability, it may not have a small consequence. Frequency/consequence (or F-N) diagrams are being increasingly referred to in decision-making, a schematic diagram being illustrated in Figure 2.

Curves such as those in Figure 2 may, in some frameworks eg [7], be used to represent an 'acceptable' line; a case which is above the line is not 'acceptable'. This expresses an aversion to low frequency/high consequence disasters. In these terms, a sequence which has not been taken account of may actually be low frequency and high consequence; and thereby be above the line. Even if this is not the case, not accounting for some sequences will have the effect of distorting an assessment in a general sense. In a more specific way it will have the effect of our thinking that we have calculated, for example, the probability of fatality, $\mathrm{P}$ (fatality), but in fact we have not. The actual $\mathrm{P}$ (fatality) is bound to be higher than we have calculated because of missed sequences; assuming accurate calculation of probabilities associated with included sequences. We may calculate what we take to be the $\mathrm{P}$ (fatality) for an option and decide that it is acceptable, but in reality we haven't actually calculated the $\mathrm{P}($ fatality). We are engaging in de facto delusion even if we acknowledge, in principle, that there are sequences which have not been taken into account. A couple of examples may help to make the point more explicitly:

Example 1: If one were conducting an analysis, say 10 years ago, of passenger death/injury/illness (DII) associated with air travel one might have come up with a simple logic tree such as that in Figure 3; ie the two causes of death/injury/illness might have quite reasonably been taken as either being due to a crash or a fire; the inclusive OR gate would include the possibility of crash and fire.

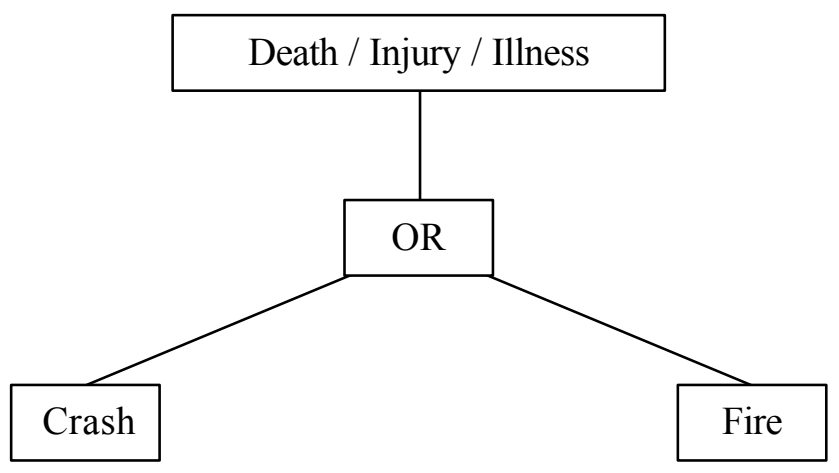

Figure 3 : Logic tree for passenger death/injury/illness associated with air travel 
The probability of the top event, $\mathrm{P}(\mathrm{DII})$, might then have been reasonably calculated on the basis of such a tree.

Within the last five years, however, it has come to be generally accepted that there are at least two other significant causes of DII viz (1) Deep vein thrombosis and (2) Crossinfection due to re-circulated air $[8,9]$. Given this, the tree of Figure 3 should be altered to that of Figure 4:

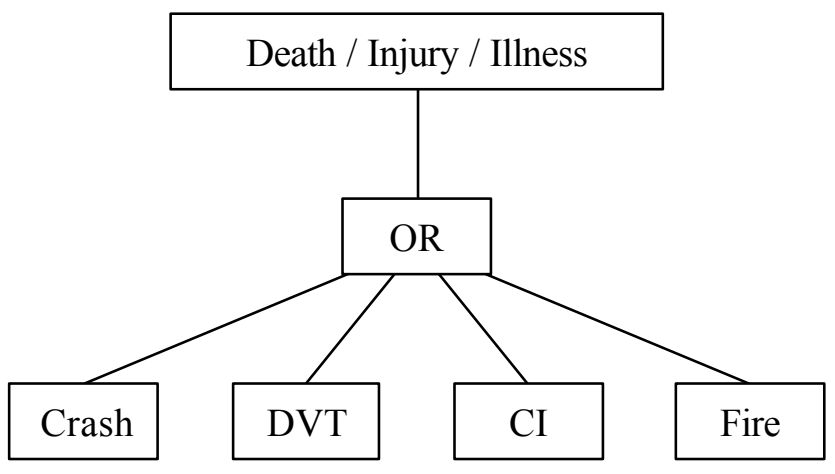

Figure 4 : Logic tree for passenger death/injury/illness associated with air travel ; updated to include deep vein thrombosis (DVT) and cross-infection (CI).

The probability of the top event is now different and, perhaps, quite significantly different to that associated with Figure 3.

Example 2: Five years ago a logic tree with a top event of 'Multiple-fatality Disaster' for the supersonic airliner Concorde may, quite reasonably, not have included the possibility of a disastrous fire due to fuel tank rupture associated with a burst tyre. Engineers may have felt quite confident about a risk assessment which ignored this possibility. Seemingly it was not thought possible that a fragment of burst tyre could rupture the fuel tank. However in July 2000 fragments from a burst tyre caused a catastrophic fire in which 113 people died. Following that an intensive effort took place to develop a new kind of tyre to reduce or eliminate the problem [10].

These examples illustrate the need to be aware, explicitly, that real-world decisionmaking and the asociated risk assessments correspond to open world models. It is necessary to try to overcome the problems of : (1) not knowing what we do not know and (2) being dismissive of seemingly 'incredible' sequences when they are not, in 
reality, incredible. More generally, we must get into the habit of being willing to question our assumptions.

\section{THE 'INCREDIBLE' MAY HAPPEN}

Sequences of events which may be dismissed as 'incredible' have a habit of happening. A recent dramatic example of this was seen in the disastrous train crash which occurred near Selby, in Yorkshire, in March 2001 which resulted in 13 dead and 75 injured [11]. In this accident a road vehicle ('Land Rover') came off of a motorway, went down a bank and on to the main east coast railway line between London and Edinburgh. Minutes later a south-bound passenger train crashed into the road vehicle and jumped the rails, but stayed upright, running on the hard surface beside the track. Moments later a north-bound freight train, running on an adjacent track, smashed head-first into the passenger train. Before the event this sequence of events would have, almost certainly, been regarded as 'incredible'. Even if such a sequence had been conceptualised it is virtually certain that no effective action would have been taken to try to avoid such a sequence occurring in the system. This links to the question of whether or not action should be taken to avoid a sequence, even if a sequence has been conceptualised and is accepted as being possible. That links to the questions : (1) 'how great is the risk associated with a given sequence?', (2) 'how accurate is our estimate?' and (3) 'what is an acceptable risk?'.

Another case worthy of mention relates to fire in tunnels. Some years ago, if a train had been seen to be on fire before entering a tunnel it might have been asumed that the system would be such as to cope with the situation before any real harm had been done. The possibility of a train being seen to be on fire before entering a tunnel and yet a disastrous fire resulting, whilst it may not have been regarded as 'incredible', might have been regarded as not meriting a lot of consideration. This has, however, happened three times since October 1995:

\{1\} The Baku, Azerbaijan, fire of October 1995 in which a fire in the underground system resulted and in which 289 lives were lost [12]

\{2\} The Channel Tunnel fire of November 1996 which produced very extensive damage and missed producing multi-fatalities only by sheer luck because the fire started in a $\mathrm{HGV}$ carrier far removed from the coach carrying the $\mathrm{HGV}$ drivers, rather than near the coach [13].

\{3\} The Kaprun Tunnel fire in Austria of November 2000 in which over 150 people died [14].

In each of these cases the system was not such as to be able to cope adequately, even though each train had been seen to be on fire before entering a tunnel. The knowledge was not used in an effective way. 
Also, before the Channel Tunnel fire, it is likely that the possibility of a fire developing to involve thirteen HGV carrier wagons, including ten becoming damaged beyond repair [13], would have been regarded as 'incredible'. However this is what happened within three years of the Channel Tunnel being open for operation.

\section{THE NEED TO QUESTION ASSUMPTIONS}

The models which are created of the real world must not be fixed and dogmatically held. A dramatic example of how a rigid model, tenaciously held, may prolong a problem is seen in the case of the so-called 'Yorkshire Ripper' [15 ]. The 'Yorkshire Ripper' murdered several women during the late 1970's. For whatever reason, according to [15], it appears that the police had it fixed in mind that the murderer had a Wear-side (North-East England) accent. This model, apparently, was strongly held for at least two years, despite explicit evidence to the contrary. Eventually the person now accepted as being responsible for the murders was apprehended; he did not have a Wear-side accent.

A different example is presented by the case of Bovine Spongiform Encephalopathy (BSE) [16,17]; a brain disease which, it is now generally accepted, has transferred from cattle to humans. For a long time the transfer to humans was effectively assumed, by the Spongiform Encephalopathy Advisory Committee (SEAC), to be impossible. Even after the accumulation of definite evidence of cross-species transfer of spongiform encephalopathies, involving several species, the possibility of transfer to humans was effectively ignored. Eventually, in 1996, SEAC and the British Government accepted that transfer to humans had, almost certainly, taken place. (Of course no hypothesis like this, or any other, could ever be proven.) The question then became "What is to be the size of the outbreak?", a question which is still unanswered.

Another case is seen in that of escape from aircraft. In 1985 there was a fire on a Boeing 737 at Manchester Airport which resulted in 54 deaths [18]. According to the design guidance all people should have been able to get out safely because tests had shown that evacuation of such an aircraft could take place in less than 90 seconds and this time was available. This assumption was shown to be disastrously wrong at the Manchester fire; because it does not take account of what people actually do in realworld situations [19]. Practical tests were carried out which were as realistic as possible and this has led to guidance for the re-design of aircraft exits.

Yet a further example is afforded by the Millennium Bridge, which was opened in June 2000, across the Thames in London. The bridge is a pedestrian suspension bridge and was closed almost immediately after being opened because it was found that the structure went into an unacceptable horizontal oscillation [20]. Seemingly the designers knew that this mode of oscillation was possible but thought that it would not present a problem because it was assumed that people walking across the bridge would be walking out of step and not in unison; any oscillation was expected to be very slight. However, in the real world, it was found that people walking across the bridge, feeling the slight oscillation, tended to alter their gait and walk in concert with the oscllation. In this way people came to walk in unison and not out of step [21]. A 
large number of people, walking in unison, then had the effect of exagerating the oscillation to the point where it became unacceptable and people started to feel 'seasick'. The bridge was then closed so that extra damping could be fitted.

In addition to the general point that assumptions need to be questioned, the two examples immediately above show the need to find out how human beings actually behave in the real world and to incorporate this knowledge into the design at an early stage; not to make naïve assumptions about human behaviour and find out later that those assumptions are wrong.

\section{CREATIVE THINKING}

Given that there will always be real-world sequences which we have not thought of, or have thought of but don't realize the significance of, it becomes necessary to try to use 'creative thinking' in carrying out risk assessments. Quite a lot has been done in the area of human problem solving in general and creative thinking in particular $[22,23]$ ; there is a need to be aware of this and consciously try to be creative in thinking about risk.

\section{BURIED RESEARCH}

Sometimes research results, which may be of considerable relevance in a particular case, are available in the open literature but the results are not noticed or are ignored. An example of this is afforded by the King's Cross Underground Station fire of 1987 in which 31 people lost their lives. The fire started on an escalator and rapidly developed into the booking hall. Research after this fire has led to the general realization of the existence of the 'Trench Effect' [24] whereby hot gases from a fire on an inclined trench tend to 'hug' the floor of the trench and cause pre-heating leading to rapid fire spread up the trench. Research very relevant to this had been published in 1971 by Magee and McAlevy [25] and reported in the book by Drysdale of 1985 [26]. Their work showed an increase in flame spread rate over strips of filter paper, the rate increasing with angle of orientation. This may be called the 'slope effect'. While the slope effect is not the same as the trench effect ( a trench having side walls) the 1971 paper should have, in principle, alerted people to the strong possibility of rapid flame spread up escalators; before the theoretical and experimental modelling which took place after the fire $[27,28,29]$.

\section{PRECAUTIONARY PRINCIPLE}

As well as having only partial knowledge about a risk, it may well be the case that there are some indications that a risk may exist but one cannot be sure. To wait for many years in order to conduct extensive research may mean that many lives would be lost in the process. In such a case it is appropriate to adopt the 'Precautionary Principle', which was enshrined in the 1992 Rio Conference on the Environment \& Development and states that "lack of full scientific certainty should not be used as a 
reason for post-poning cost-effective measures to prevent environmental degradation". The principle may be applied to risk in general and this has been put forward by the Commission of the European Union [30]. An example is afforded by mobile telephones. According to [31] "There is currently no evidence that mobile phones harm users... But some studies show that cell-phones...do have some sort of biological effect on the brain." It is concluded by Tattersall, quoted in [31], "If you have a developing nervous system, it's known to be more susceptible... so if phones did prove to be hazardous, which they haven't yet, it would be sensible" ; ie to limit phone use, at least by children.

The general rule should be: because we don't know what we don't know, we should err on the cautious side.

\section{SOCIO-ECONOMIC FACTORS}

It may happen that a particular sequence is known to be a possibility but nothing really effective is done about it for socio-economic reasons. An example of this is afforded by the case of upholstered furniture. The hazards of furniture filled with standard polyurethane foam (PUF) became evident during the 1970's and was reported in the scientific literature, eg [32]. During the late 1970's there was a series of domestic fires, involving such furniture, which resulted in deaths and injuries. These were accompanied by a high frequency of reports of these fires on the television screens, coupled with fire brigade officers being interviewed. At long last a British Standard [33] came into effect and a regulation which required that after f $^{\mathrm{t}}$ January 1983 furniture on sale should be able to withstand, for example, a discarded cigarette. It might be argued that, without a series of domestic fires hitting the screens, such a regulation might have taken even longer to materialize. (Even then, that Standard only addressed ignitability and did not consider what happens after ignition. A larger ignition source than considered in that Standard might ignite the PUF causing a rapidly burning fire generating large quantities of smoke and toxic gases.)

Another case of interest is given by the regulations covering chemical plants. Following the Flixborough disaster of 1974 [34] and the Seveso disaster of 1976 [35], the Control of Industrial Major Accident Hazards (CIMAH) Regulations were introduced in 1984 for onshore chemical plants. The main content of the regulations was the introduction of the 'Safety Case', to be prepared by the plant owner. The purpose of a safety case is, in essence, to identify hazards, assess hazards and demonstrate that adequate safeguards are present to control the hazards, 'so far as is reasonably practicable'.

Offshore installations are, essentially, chemical plants surrounded by sea instead of being surrounded by land. In addition, offshore installations have the additional problems of:

(1) Shortage of space, meaning that operations tend to be crushed together in a small area. That is, offshore installations are very compact by comparison with onshore 
installations. (2) Being surrounded by sea means escape is difficult and (3) Being surrounded by sea means fire brigade access is very difficult or impossible.

Given these extra problems one might reasonably say, as a general rule, that offshore installations are even more problematic with regard to risk than onshore installations. It would not have taken a great leap of imagination to have included offshore installations in the CIMAH regulations or to have made up similar regulations for offshore.

Instead, however, socio-economic factors were such that society had to wait for the loss of 167 lives in the Piper Alpha disaster of 1988 before the Cullen Report [36] recommended bringing in a safety case regime, amongst other changes, for offshore installations. Had such regulations been introduced in 1984, along with the CIMAH regulations, the great loss of life at Piper Alpha might, just possibly, have been avoided.

Another case is provided by the Challenger space shuttle disaster of 1986, in which pressure to launch over-rode concerns about the O-ring seals [37].

\section{DISCUSSION}

In the feature film 'Contact' (based on a novel by Carl Sagan) the character played by the actress Jodie Foster travels in a space-craft to a planet orbiting Vega, 26 light years away, in search of extra-terrestrial intelligence; having had a signal from there telling humans how to construct a machine to get there. As she is about to get on the craft an engineer gives her a cyanide suicide pill saying, after she at first refuses, "we can think of a thousand reasons why you might need this pill, but mainly it's for the reasons we can't think of ". The engineer in the film had the right spirit; it is necessary to try to be open and explicit. That is, it is necessary to try to allow for the unanticipated explicitly.

A number of ramifications emerge from this starting point which have been explored to some degree in this article; the main points are summarized below:

$\{1\}$ There may be possible sequences which a modeller does not know about.

\{2\} There may be possible sequences which a modeller does know about but which are effectively ignored in decision-making for one reason or another. That is, sequences may be effectively ignored because they are regarded as 'incredible' and their significance is under-estimated or for other, eg socio-economic, reasons.

Given the above, we need to be willing to question our assumptions and be cautious in decision-making on risk. It also follows that it is necessary to consciously try to be creative in risk assessments as well as being open and explicit. Further, it is necessary to try to apply different ways of thinking to a given problem, including applying different kinds of models with different assumptions; in an attempt to get an overall view in a given case. Also, of course, models need to be used in conjunction with other knowledge and experience [38]. In essence, we are not gods; there will always be something which has not been thought of. Because of this it is necessary to be as 
open, explicit and cautious as possible in decision-making on risk in an attempt to allow for the un-anticipated.

\section{REFERENCES}

[1] Beck, V.R. \& Yung, D., 'The Development of a Risk-Cost Assessment Model for the Evaluation of Fire Safety in Buildings', $4^{\text {th }}$ Int Symposium on Fire Safety Science, pp 817-828, Ottawa, 13-17 July 1994, Int Assn. for Fire Safety Science

[2] Reducing Risks, Protecting People, Discussion Document, Risk Assessment Policy Unit, Health \& Safety Executive, 1999

[3] Beard, A.N., 'Fire Models \& Design', Fire Safety Journal, 28, pp 117-138, 1997

[4] Beard, A.N., 'On a priori, blind and open Comparisons Between Theory and Experiment', Fire Safety Journal, 35, pp 63-66, 2000

[5] Plato, Meno, contained in Plato Volume II: Laches, Protagoras, Meno, Euthydemus; translated by W.R.M.Lamb, Heinemann, London, 1967

[6] Blockley, D., Engineering Safety, McGraw-Hill, London, 1992

[7] The Tolerability of Risk from Nuclear Power Stations, Health \& safety Executive, London, 1988, Her Majesty's Stationery Office

[8] Rowlands, B., 'Are Planes Bad for You?', The Daily Telegraph, $3^{\text {rd }}$ July 2000

[9] Branigan, T., 'Airlines refuse to help research on killer blood clots', The Guardian, $11^{\text {th }}$ June 2001

[10] Webster, B., 'BA Concordes to be fitted with tough new tyres', The Times, $8^{\text {th }}$ June 2001

[11] 'A Disaster that Beggars Belief', The Scotsman, $1^{\text {st }}$ March, 2001

[12] Hedefalk, J. \& Rohlen, P., 'Lessons from the BAKU Subway Fire', $3^{\text {rd }}$ International Conference on Safety in Road and Rail Tunnels, (SIRRT3), pp 15-28, Nice, 9-11 March 1998, orgainzed by Dundee University and International Technical Conferences Ltd.

[13] Inquiry into the Fire on the Heavy Goods Vehicle Shuttle 7539 on $18^{\text {th }}$ November 1996, Channel Tunnel Safety Authority, May 1997, The Stationery Office, London

[14] 'How did a train that they called 'fire-proof' become an inferno?', The Independent,

$13^{\text {th }}$ November 2000

[15] The Hunt for Wear-side Jack, Independent Television (ITV), $6^{\text {th }}$ June 2001

[16] B.J. Ford, BSE-The Facts, Corgi, London, 1996

[17] Dealler, S., Lethal Legacy : BSE-The Search for the Truth, Bloomsbury, London, 1996

[18] Fortune, J. \& Peters, G., Learning from Failure, Wiley, Chichester, 1995

[19] Muir, H., 'Human Factors in Escape from Fires', International Seminar on Human

Factors in Tunnel Safety, Madrid, $5^{\text {th }}$ April, 2001. Organized by Dundee University and Independent Technical Conferences Ltd.

[20] Wright, O. \& Kite, M., 'Bridge Shuts for Work to Cure its Wobbly Way',

The Times, p 9, $13^{\text {th }}$ June 2000

[21] Sample, I., 'Bad Vibrations', New Scientist, p 14, $8^{\text {th }}$ July, 2000 
[22] Newell, A. \& Simon, H.A., Human Problem Solving, Prentice-Hall, Englewood Cliffs, , New Jersey, 1972

[23] de Bono, E., Serious Creativity, Harper Collins, London, 1995

[24] Atkinson, G.T., Drysdale, D.D. \& Wu, Y., 'Fire Driven Flow in an Inclined Trench', Fire Safety Journal, 25, pp 141-158, 1995

[25] Magee, R.S. \& McAlevy, R.F., 'The Mechanism of Flame Spread',

Jnl of Fire \& Flammability, 2, pp271-297, 1971

[26] Drysdale, D.D., Introduction to Fire Dynamics, Wiley, Chichester, 1985

[27] Simcox, S., Wilkes, N.S. and Jones, I.P.,

Fire at King's Cross Underground Station, 18 $8^{\text {th }}$ November 1987: Numerical Simulation of the Buoyant Flow and Heat Transfer, AEA Technology, Harwell Laboratory,

Report AERE-G4677, 1988

[28] Cox, G., Chitty, R. and Kumar, S., 'Fire Modelling and the King's Cross Fire Investigation', Fire Safety Journal, 15, pp103-106, 1989

[29] Moodie, K. \& Jagger, S.F., 'The Technical Investigation of the Fire at London's King's Cross Underground Station', Jnl of Fire Protection Engineering, $\underline{3}$, pp 49-63, 1991

[30] Communication from the Commission: On the Precautionary Principle, COM(2000)1, Commission of the European Communities, Brussels, 2000.

[31] Graham-Rowe, D. \& Coghlan, A., 'For Adults Only', New Scientist, 166 (2238), p5, $13^{\text {th }}$ May 2000

[32] Woolley, W.D., Ames, S.A., Pitt, A.I. \& Murrell, J.V., 'Fire Behaviour of Beds \& Bedding Materials', Fire Research Note 1038, Fire Research Station, U.K., 1975

[33] BS5852: Part 1; 1979. Fire Tests for Furniture; British Standards Institution, London, 1979.

[34] The Flixborough Disaster, Report of the Court of Inquiry, Her Majesty's Stationery Office, London, 1975

[35] King, Ralph, Safety in the Process Industries, Butterworth-Heinemann, London, 1990

[36] Cullen, D., The Public Inquiry into the Piper Alpha Disaster, Her Majesty's Stationery Office, London, 1990

[37] Smith, R.J., “Inquiry Faults Shuttle Management”, Science, 232, pp 1488-1489, 1986

[38] Beard, A.N., "Limitations of Computer Models", Fire Safety Journal, 18, pp 375391,1992 